\title{
Optimization study of hybrid spot-welded/bonded single-lap joints
}

\author{
R.D.S.G. Campilho, A.M.G. Pinto, M.D. Banea, L.F.M. da Silva
}

\begin{abstract}
Joining of components with structural adhesives is currently one of the most widespread techniques for advanced structures (e.g., aerospace or aeronautical). Adhesive bonding does not involve drilling operations and it distributes the load over a larger area than mechanical joints. However, peak stresses tend to develop near the overlap edges because of differential straining of the adherends and load asymmetry. As a result, premature failures can be expected, especially for brittle adhesives. Moreover, bonded joints are very sensitive to the surface treatment of the material, service temperature, humidity and ageing. To surpass these limitations, the combination of adhesive bonding with spot-welding is a choice to be considered, adding a few advantages like superior static strength and stiffness, higher peeling and fatigue strength and easier fabrication, as fixtures during the adhesive curing are not needed. The experimental and numerical study presented here evaluates hybrid spot-welded/bonded single-lap joints in comparison with the purely spot-welded and bonded equivalents. A parametric study on the overlap length ( $\left.L_{O}\right)$ allowed achieving different strength advantages, up to 58\% compared to spot-welded joints and 24\% over bonded joints. The Finite Element Method (FEM) and Cohesive Zone Models (CZM) for damage growth were also tested in Abaqus ${ }^{\mathbf{s}}$ to evaluate this technique for strength prediction, showing accurate estimations for all kinds of joints.
\end{abstract}

Keywords: Epoxy/epoxies, Steels, Finite element stress analysis, Joint design, Cohesive zone models

\section{Introduction}

Joining of components is usually accomplished by mechanical fastening, welding or adhesive bonding. Joining with structural adhesives is nowadays one of the most widespread techniques for advanced structures (e.g., aerospace, aeronautical, automotive or sports equipment) because it offers more uniform distribution of stresses, since drilling operations are not needed, and it distributes the load over a larger area than mechanical joints, it increases fatigue life and weight saving, and it prevents corrosion between dissimilar materials. However, peak stresses tend to develop near the overlap edges because of differential straining between the adherends at the overlap and load asymmetry $[1,2]$. As a result, premature failures can be expected, especially for brittle adhesives. Additionally, bonded joints are very sensitive to the surface treatment, service temperature, humidity and ageing [3-5]. Hybrid joints combine adhesive bonding with another joining technique (e.g., weld-bonded, rivet-bonded or fastenbonded unions), and have previously been considered to improve damage tolerance (either static or fatigue) or repair of structures, combined with ease of fabrication because of adhesive curing without fixtures requirement $[6,7]$. Besides, the joint geometry and materials can be adjusted for a specific application, depending on design goals and service conditions [8]. Regarding fastenbonded joints, few works were published in the recent years $[9,10]$, although these are already common in automotive applications [8]. Lee et al. [11] studied fasten-bonded joints and the influence of some parameters on the joints strength, with emphasis on Failure Area Index theoretical prediction technique, which resulted in a maximum deviation of $23 \%$ to the experiments. The analytical work of Hart-Smith [12] is one of the first ones regarding bolt-bonded joints, by the consideration of stepped joints with composite adherends, using nonlinear continuum mechanics theories to achieve a fair reproduction of the test results. Kelly [13] analyzed bolt-bonded single-lap joints with composite adherends using a three-dimensional FEM technique that included the effects of the bolt-hole contact and the nonlinear material behavior. Results showed that this technology benefits the joint strength, especially for flexible joints. Rivetbonded joining has equally been studied (e.g. fatigue strength optimization of riveted unions with adhesive reinforcement [14]). The combination of adhesive bonding with resistance spot-welding (weld-bonded joints) is also feasible, and a large number of works are currently published regarding this technology, 
either for static $[15,16]$ or fatigue studies $[17,18]$. In conventional spot-welding, the faying surfaces are joined by melting of the adherends through the flow of electric current, which in turn increases the temperature at the interface due to electrical insulation. Heating is performed by a short-time pulse of low voltage and high amperage current to form a fused nugget of welded metal $[19,20]$. The weld nugget forms locally at the interface between faying surfaces and it does not extend up to the outer surfaces of the joint [7], while its size and shape mainly rely on the geometry of the welding electrodes. The synergy between adhesive bonding and spot-welding provides competitive advantages to the traditional adhesive bonds $[11,21,22]$ like superior strength and stiffness, higher resistance to peeling and easier fabrication, as fixtures during the adhesive curing are not needed [7]. Compared to spot-welding, weld-bonded joints excel in improved fatigue characteristics, because of the reduction of stress concentrations at the weld-nugget periphery. Evaluated against bonded joints, weld-bonded unions result in a more uniform stress distribution than bonded joints, justifying for both situations the improved characteristics of these hybrid joints $[22,23]$. Thus, by combination of spot-welding and bonding, their individual disadvantages are eliminated. Currently, many load bearing components in aircrafts, helicopters, the shell of missiles, spaceship sounders and vehicle structures are produced by weldbonded techniques [24-27]. Weld-bonded joints were initially developed for aircraft applications [24], and the flow-in method was employed at initial development stages of this technology, in which the components were firstly spot-welded, and a lowviscosity adhesive subsequently filled the bonding regions by capillarity, followed by heating for curing. The weld-through quickly became a viable alternative to permit higher viscosity adhesives to be used. By this technique, the components are primarily bonded, and the bonded region is then spot-welded before curing of the adhesive, i.e., within the working time (WT) of the adhesive $[7,28]$. This process was not fully understood until recently due to lack of systematic theoretical and experimental investigations, e.g., the experimental work of Charbonnet et al. [29] and the experimental/metallurgical and numerical studies of Darwish and Ghanya [7] and Darwish [25]. Charbonnet et al. [29] tested weld-bonded unions with three grades of mild steel for the adherends and two kinds of adhesives (epoxy and rubber sealer). A higher overall performance was found when compared to conventional spot-welded joints. The work has also proved that conventional spot-welders can be used for weld-bonding. Regarding the strength of weld-bonded joints, different studies showed, either by testing or FEM stress analyses, the benefits of single-lap weld-bonded joints compared to spot-welded joints under static or fatigue loadings [28,30-32]. Melander et al. [18] also testified the higher efficiency of weld-bonding compared to spot-welding on a peel test geometry. Santos et al. [28] published a numerical/ experimental investigation of weld-bonded single-lap joints between steel adherends, for optimization of material and fabrication parameters. Three adhesives were tested (epoxy and methacrylate-based), considering varying time intervals between the bonding and welding operations. The numerical analysis allowed the optimization of welding parameters, while for the experiments the weld-through fabrication method was selected. Three conditions were tested: welding immediately after bonding and assembly ( $0 \%$ of the WT), at $50 \%$ of the WT and at $100 \%$ of the WT. Testing revealed a premature adhesive layer debonding, whilst the maximum load was governed by the spot weld. However, welding at $100 \%$ of the WT further anticipates the premature failure of the adhesive layer. In the work of Moroni et al. [8] weld-bonded, rivet-bonded and clinch-bonded joints were compared to adhesive, spot-welded, riveted or clinched joints. The Design of Experiments was used to test the influence of parameters such as materials, geometry (adherend thickness and weld/rivet/clinch pitch) and environment on the joints strength, stiffness and energy absorption. The main advantage of weld-bonding was related to the substantial increase in energy absorption, although a non-negligible increase of stiffness and strength was also found. The adherend thickness was found to highly influence welded and weld-bonded joints, as the weld nugget diameter increased with the adherend thickness, while it had a small influence for bonded joints, in this case related to the reduction of peel effects [1]. A significant improvement under ageing and high temperature was also found with weld-bonded joints compared to bonded joints. Despite the reported studies, failure load predictions for hybrid joints are scarce in the literature ([11] for fasten-bonded joints). Additionally, the failure process of weld-bonded joints is still not fully understood, and established failure criteria do not exist [22], mainly because of the co-existence of the weld nugget and adhesive layer, which makes the stress and strain analyses more complex [22]. As the available numerical techniques for bonded joints by the FEM combined with CZM analyses for fracture prediction are quite accurate, effective and economic [33,34], it is essential to test this technique for weld-bonded joints. Actually, provided that the predictions are accurate by a faithful representation of the phenomena involved, hybrid joint design will become highly facilitated, allowing an easier optimization and reduction of design costs.

In this work, an experimental and numerical study was carried out on hybrid weld-bonded single-lap unions, in comparison with the spot-welded and adhesively bonded equivalents, considering a ductile adhesive. A parametric study on $L_{0}$ allowed proper characterization of the strength advantages of this hybrid technique under different conditions. The FEM work was performed in Abaqus $^{\text {s }}$, comprising a stress analysis that provided a background for discussion of the presented results. CZM were used for damage simulation, allowing the evaluation of this technique for the strength prediction and design of weld-bonded joints. a

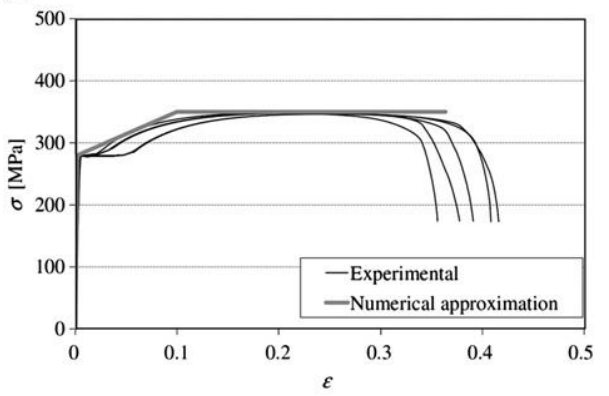

b

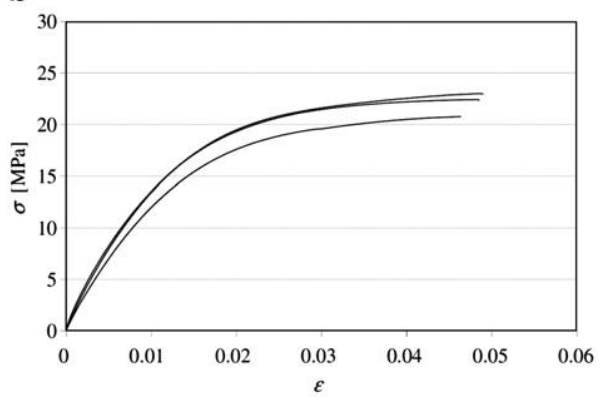

Fig. 1. S-e curves of the low carbon steel used and respective approximation for the FEM analysis (a) and $\mathbf{S}-\mathrm{e}$ curves of adhesive Araldite $\mathbf{S} 2015$ (b). 


\section{Experimental work}

\subsection{Characterization of the materials}

A low carbon steel was selected for the adherends, characterized by good weldability, ductility and low cost, which makes it a good option for many engineering applications. The raw material was provided as $2 \mathrm{~mm}$ laminated sheets, and it was properly characterized according to the ASTM-E8M-04 standard. Fig. 1(a) shows the engineering stress-strain (s-e) curves for five specimens and respective approximation for simulation in Abaqus ${ }^{\mathbf{s}}[35,36]$. Tests revealed a Young's modulus $(E)$ of $204.3272 .40 \mathrm{GPa}$, an initial yield stress of $279.1170 .82 \mathrm{MPa}$, a maximum strength of 347.517 $0.93 \mathrm{MPa}$ and a failure strain of $36.3672 .45 \%$. For the adhesive selection, the wetting characteristics to the bonding surfaces were considered to achieve a high quality bond. The WT of the adhesive was also equated, to prevent premature adhesive curing and increased electrical insulation, resulting in excessive heat generation and metal expulsion, and subsequent damage to the adhesive, or obstruction to the welding operation by canceling of the current flow [28]. The adhesive Araldites 2015, holding a WT of $35 \mathrm{~min}$, was selected and characterized for the FEM analysis. The adhesive bulk specimens for mode I loading were fabricated according to the NF T 76-142 French standard. The Thick Adherend Shear Tests (TAST) for mode II loading followed the guidelines of the standard ISO 11003-2:1999. Fig. 1(b) shows, as an example, s-e curves in mode I loading. More details on the fabrication procedure and characterization of the adherends and adhesive can be found in Refs. [35-37]. The fracture toughness in tension $\left(G_{n}^{c}\right)$ and in shear $\left(G_{s 1}^{c}\right)$ were derived in previous works by Double-Cantilever Beam and End-Notched Flexure tests, respectively [33,34], whilst the fracture toughness in the tearing mode of loading $\left(G_{2}^{c}\right)$ was equaled to $G_{s 1}^{c}[2,38]$. Table 1 summarizes the collected data [37].

\subsection{Joint geometries}

Fig. 2 depicts the geometry of the joints, applicable to the welded, bonded and weld-bonded joints. The characteristic dimensions were defined as (in mm) $L_{O} 1 / 415,30,45$ and 60 , width $b 1 / 425$, total length between grips $L_{T} 1 / 4150$, adherend thickness $t_{P} 1 / 42$ and adhesive thickness $t_{A} 1 / 40$ for the welded joints and $t_{A} 1 / 40.2$ for the bonded and weld-bonded joints. The value of $t_{A}$ was selected as the maximum allowable for welding, thus minimizing stress concentrations at the weld-nugget periphery [16]. For the welded joints, only $L_{O} 1 / 415 \mathrm{~mm}$ was considered. For the welded and weld-bonded joints, the spot is located at the midlength of $L_{O}$. The joint faying surfaces were prepared by manual abrasion with 220 mesh sandpaper, followed by wiping with acetone, and the joints were fabricated using a bonding apparatus

Table 1

Properties of adhesive Araldites 2015 [37]

\begin{tabular}{ll}
\hline Property & \\
\hline & \\
Young's modulus, $E[\mathrm{GPa}]$ & 1.8570 .21 \\
Poisson's ratio $\mathrm{n}^{\mathrm{a}}$ & 0.33 \\
Tensile yield strength $\mathrm{S}_{y}[\mathrm{MPa}]$ & 12.6370 .61 \\
Tensile failure strength $\mathrm{S}_{f}[\mathrm{MPa}]$ & 21.6371 .61 \\
Tensile failure strain $\mathrm{e}_{f}[\%]$ & 4.7770 .15 \\
Tensile toughness $G_{n}^{c}[\mathrm{~N} / \mathrm{mm}]$ & 0.4370 .02 \\
Shear modulus $G[\mathrm{GPa}]$ & 0.5670 .21 \\
Shear yield strength $\mathrm{t}_{y}[\mathrm{MPa}]$ & 14.671 .3 \\
Shear failure strength $\mathrm{t}_{f}[\mathrm{MPa}]$ & 17.971 .8 \\
Shear failure strain $\mathrm{g}_{f}[\%]$ & 43.973 .4 \\
Shear toughness $G_{1}^{c}[\mathrm{~N} / \mathrm{mm}]$ & 4.7070 .34 \\
\hline
\end{tabular}

${ }^{a}$ Manufacturer's data.

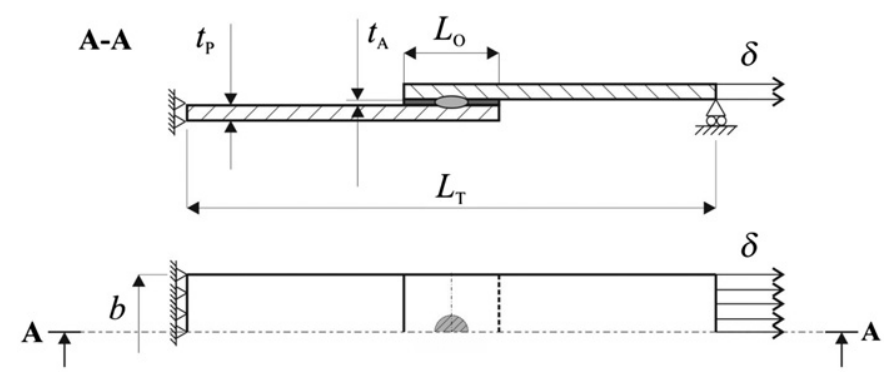

Fig. 2. Geometry and characteristic dimensions of the single-lap specimens.

that allowed the proper adherend alignment. The weld-bonded joints were fabricated by the weld-through technique, with the welding operation taking place at a maximum of $10 \mathrm{~min}$ after bonding. During welding, the adhesive usually degrades and carbonizes at around $1-2 \mathrm{~mm}$ outside the nugget periphery [22], not contributing to the load-bearing capability of the joints [39]. For the bonded and weld-bonded joints, $t_{A}$ was achieved by placement of $\varnothing 0.2 \mathrm{~mm}$ nylon wires around the overlap region, jointly with the application of pressure with grips. A CEA ${ }^{\mathbf{s}}$ NKLT28 spot-welder was used to fabricate the spot-welded and weldbonded joints, equipped with truncated cone shape electrodes (Ø6 $\mathrm{mm}$ at the contacting edges) in accordance with the ISO 5182 standard. The electrode clamping load is adjustable (up to $2.2 \mathrm{kN}$ ) and applied by a foot pedal. The spot-welder holds a maximum short-circuit current of $14 \mathrm{kA}$ and a nominal welding power of $25 \mathrm{kVA}$. The input parameters are squeeze time, representing the time (in $50 \mathrm{~Hz}$ cycles of applied current) between the plates squeezing and the beginning of welding, set to 3 cycles, the upslope, representing the time needed to proportionally reach the defined welding current, set to 5 cycles, the welding time, defining the duration of the current flow, considered at 35 cycles, and the welding current, providing the percentile of the maximum current supplied by the spot welder, set at $45 \%$ (E $6.3 \mathrm{kA}$ ). Despite the reported welding parameters used throughout this work, an initial study was carried out on the influence of these parameters on the joints behavior. Before testing, tabs were glued at the specimens edges for a correct alignment. The joints were tested 1 week after fabrication for complete curing of the adhesive (bonded and weld-bonded joints). The tests were carried out in a Shimadzu AG-X 100 testing machine with a $100 \mathrm{kN}$ load cell, at room temperature and under displacement control $(1 \mathrm{~mm} /$ $\mathrm{min})$. The testing machine grips displacement was used to build the $P-\mathrm{d}$ curves. Five specimens were tested for each joint configuration, with at least four valid results.

\section{Numerical analysis}

\subsection{Analysis conditions}

The FEM analysis was performed in Abaqus ${ }^{\text {s }}$, aiming to check the suitability of its CZM embedded formulation to predict the strength of the bonded, welded and weld-bonded joints, and it accounted for geometrical non-linear effects [40]. The weld nugget and adhesive were fully modeled by the triangular CZM laws presented in Section 3.2. In the welded and weld-bonded models, a few simplifications were employed, such as the nonconsideration of the steel properties variations near the nugget due to the applied thermal cycle [41,42], or the minor electrode indentation at the welding loci. The adhesive properties also relate to room temperature curing, despite the thermal cycle applied during welding [28], which is prone to degrade the adhesive [43], and adhesive degradation at the spot periphery 
a

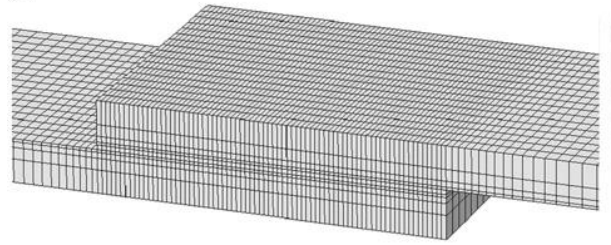

b

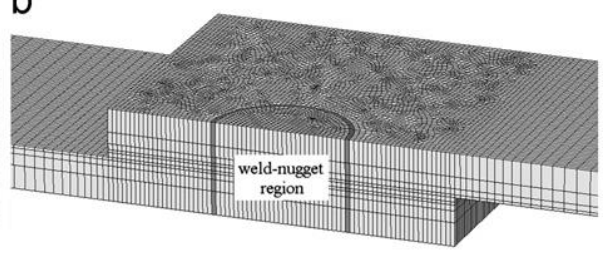

Fig. 3. Mesh details at the overlap for the $L_{O^{1} / 4} 15 \mathrm{~mm}$ adhesively bonded (a) and weld-bonded (b) models (view of the symmetry plane).

was also neglected [22]. The three-dimensional models were built with longitudinal symmetry conditions (Fig. 2). Fig. 3 shows the meshes for the $L_{O} 1 / 415 \mathrm{~mm}$ bonded (a) and weld-bonded (b) joints at the overlap, emphasizing on the smaller elements at the spotweld outer boundary and also towards the contacting region between adherends, because of the respective concentrations of stresses $[22,28,44]$. The models used 8-node hexahedral solid elements (C3D8R from Abaqus ${ }^{\text {s) }}$ ) and COH3D8 8-node cohesive elements. The joints were clamped at one of the edges, while the other edge was subjected to a tensile displacement concurrently with transverse restraining, to simulate real testing conditions $[45,46]$. The thin adhesive layer was modeled by a single row of cohesive elements [36] incorporating a mixed-mode tractionseparation law between the element faces, including the stiffness of the adhesive layer, as defined further in this work. The weldnugget was modeled in a similar fashion, considering a $0.2 \mathrm{~mm}$ thickness zone collinear with the adhesive layer to account for failure of the weld-nugget, whilst the surrounding steel portion was modeled using the previously defined bulk steel properties. This choice was made despite the large and continuous gradient of steel properties between the weld-nugget and the bulk steel for simplification purposes [22]. The proposed modeling technique is currently implemented within Abaqus ${ }^{\mathbf{s}} \mathrm{CAE}$ suite and will be briefly described in the following section.

\subsection{Cohesive zone modeling}

$\mathrm{CZM}$ are based on a relationship between stresses and relative displacements (in tension, shear or tearing) connecting paired nodes of the cohesive elements (Fig. 4), to simulate the elastic behavior up to the cohesive strength ( $t_{n}$ in tension, $t_{s 1}$ in shear or $t_{\mathrm{s} 2}^{0}$ in tearing) and subsequent softening, to model the degradation of material properties up to failure [47]. The shape of the softening region can also be adjusted to conform to the behavior of different materials or interfaces [40]. The areas under the traction-separation laws in tension, shear or tearing $\left(G_{n}, G_{s 1}\right.$ or $G_{s 2}$, respectively) are equaled to $G_{n}^{c} G_{s 1}^{c}$ or $G_{s 2}^{c}$ in the respective order. Under pure loading, damage grows at a specific integration point when stresses are released according to the respective damage law. Under a combined loading, stress and energetic criteria are often used to combine tension, shear and tearing [36]. The triangular law (Fig. 4) assumes an initial linear elastic behavior followed by linear degradation. Elasticity is defined by a constitutive matrix $(\mathrm{K})$, containing the stiffness parameters and relating stresses and strains across the interface [48]:

$\mathbf{t}=\left\{\begin{array}{l}t_{n} \\ t_{s 1} \\ t_{s 2}\end{array}\right\}=\left[\begin{array}{lll}K_{n n} & K_{n s 1} & K_{n s 2} \\ K_{n s 1} & K_{s 1 s 1} & K_{s 1 s 2} \\ K_{n \leq 2} & K_{s 12} & K_{s 252}\end{array}\right]\left\{\begin{array}{l}\varepsilon_{n 2} \\ \varepsilon_{s 1} \\ \varepsilon_{s 2}\end{array}\right\}=\mathbf{K} \varepsilon$.

A suitable approximation for thin adhesive layers [49] and weld-nugget debonding is provided with $K_{n n} 1 / 4 E, K_{s 1 s 1} 1 / 4 K_{s 2 s 2} 1 / 4 G$, $K_{n s 1} 1 / 4 K_{n s 2} 1 / 4 K_{s 1 s 2} 1 / 40$ ( $G$ is the shear modulus). Damage initiation can be specified by different criteria. In this work, the quadratic nominal stress criterion was considered for the initiation of

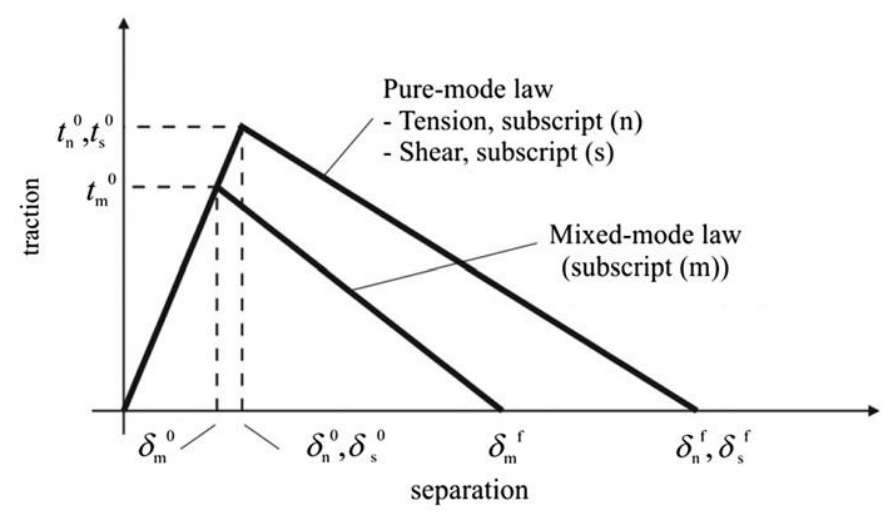

Fig. 4. Traction-separation law with linear softening law available in Abaqus $\mathbf{s}$ (the subscript $\mathrm{s}$ is valid either for shear, s1, or tearing, s2).

damage, already shown to give accurate results [40] and expressed as [48]

$$
\left\{\frac{\left\langle t_{n}\right\rangle}{t_{n}^{0}}\right\}^{2}+\left\{\frac{t_{s 1}}{t_{s 1}{ }^{0}}\right\}^{2}+\left\{\frac{t_{s 2}}{t_{52}{ }^{0}}\right\}^{2}=1 .
$$

$<$ are the Macaulay brackets, emphasizing that a purely com- pressive stress state does not initiate damage [50]. After the mixed-mode cohesive strength is attained $\left(t^{0}\right.$ in Fig. 4) by the fulfilment of Eq. (2), the material stiffness is degraded. Complete separation is predicted by a linear power law form of the required energies for failure in the pure modes [48]:

$$
\frac{G_{m}}{G_{m}^{c}}+\frac{G_{s 1}}{G_{s 1}^{c}}+\frac{G_{s 2}}{G_{s 2}{ }^{c}}=1
$$

\section{Results and discussion}

\subsection{Parametric study on the welding parameters}

The nugget strength in welded and weld-bonded joints is known to significantly vary with the welding parameters [22]. To fully understand these effects, the failure mechanisms and the perceived influence on the adhesive curing, three sets of welding parameters were tested (in the following order-squeezing time, upslope, welding time and welding current): $1-3 / 5 / 30 / 40,2-3 / 5 /$ $35 / 45$ and 3-3/5/43/53 (proposed by the manufacturer for $t_{P} 1 / 42 \mathrm{~mm}$ carbon steel plates). Fig. 5(a) shows representative $P-$ $\mathrm{d}$ curves for each one of these three conditions. Table 2 provides the collected data for 5 specimens of each set. The effect of the welding parameters is notorious, with a brittle shear fracture of the weld-nugget for set 1 , a weld-nugget fracture after plasticization of the adherends initiating at $\mathrm{d} E \mathbf{E} 0.65 \mathrm{~mm}$ for set 2 and an adherend failure near the weld-nugget for set 3 . Regarding the visible effect of each parameter set on the weld-bonded joints, sets 1 and 2 cause only a minor heating of the adherends at the overlap and do not significantly change the adhesive curing cycle, 
a

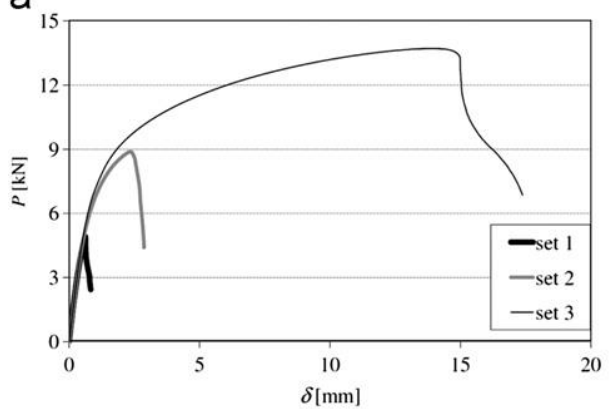

b

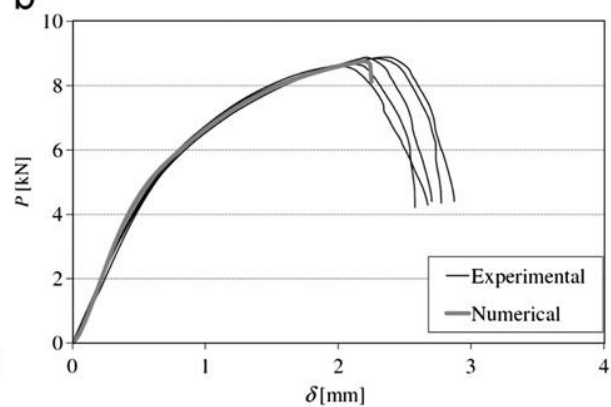

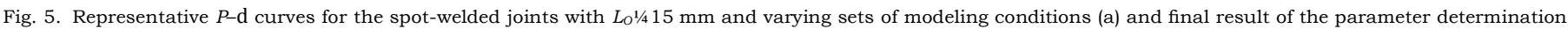
method by comparison between the experiments and FEM simulation (b)

Table 2

Strength and maximum load displacement average data (with respective deviations) for five spot-welded joints of each welding condition.

\begin{tabular}{lrl}
\hline $\begin{array}{l}\text { Welding } \\
\text { condition }\end{array}$ & Strength $[\mathrm{N}]$ & $\begin{array}{l}\text { Maximum load } \\
\text { displacement }[\mathrm{mm}]\end{array}$ \\
\hline 1 & 49127171 & 0.65270 .102 \\
2 & 87797125 & 2.18670 .149 \\
3 & 13,8067273 & 13.51970 .923 \\
\hline
\end{tabular}

Table 3

Cohesive parameters of adhesive Araldites 2015 and weld-nugget for CZM modeling [36,40].

\begin{tabular}{lcc}
\hline Property & 2015 & Weld-nugget \\
\hline$E[\mathrm{GPa}]$ & 1.85 & 204.32 \\
$G[\mathrm{GPa}]$ & 0.56 & 78.58 \\
$t_{\mathrm{R}}^{0}[\mathrm{MPa}]_{\mathrm{MPa}]}$ & $21.8^{3}$ & 539 \\
$t_{s 1} 1 / 4 t_{s 2}$ & & 118 \\
$\left.G_{\mathrm{q}}^{c}[\mathrm{~N} / \mathrm{mm}] / \mathrm{Nm}\right]$ & 9.73 & 238 \\
$G_{s 1} 1 / 4 G_{s 2}$ & & \\
\hline
\end{tabular}

while set 3 immediately solidifies the adhesive during welding (with visible burning at the overlap periphery), anticipating its degradation. As a result of these tests, set 2 of welding parameters was selected, as it provides an acceptable ductility of the joints without affecting the adhesive layer properties.

\subsection{Definition of cohesive parameters}

Table 3 shows the parameters introduced in Abaqus ${ }^{s}$ for the simulation of damage growth in the adhesive layer and weldnugget $[36,40]$. The adhesive parameters were estimated from the data of Table 1, considering the average values of failure strength

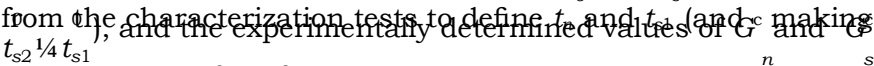
(equally with $G_{s 2}^{c} 1 / 4 G_{s 1}^{c}$ ). The weld-nugget parameters are known to substantially differ from the bulk steel properties due to the thermal strengthening induced by the welding cycle. Actually, in the work of Chang and Shi [22], a large variation of yield strength was found between the base metal and the weld-nugget, the latter having a yield strength of nearly $400 \%$ of the base metal. As a result of these property gradients, the weld-nugget parameters were estimated by fitting between the experimental and FEM $P-\mathrm{d}$ curves of the welded joints considering set 2 of welding properties, using a trial and error analysis, such that an empirical law can be established to accurately model the weld-nugget failure, equally allowing extrapolation for the simulation of the weld-

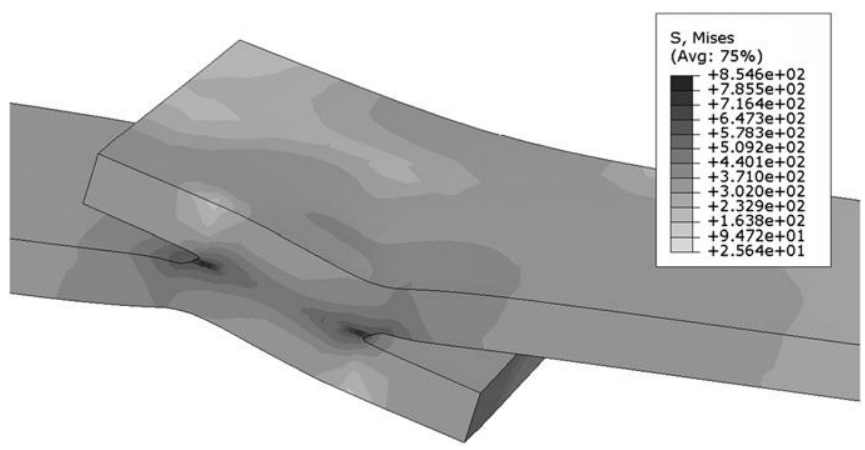

Fig. 6. Von Mises equivalent stresses in the spot-welded joints in the overlap region (view of the symmetry plane)

bonded joints. Fig. 5(b) shows the final result of the parameter determination method by comparison between the experiments and FEM simulation.

\subsection{Stress analysis}

The present stress analysis, aiming to provide a basis for discussion of the results that follow, includes stress field plots at the overlap region for the welded joint immediately before failure, for an assessment of the typical adherend/weld nugget stress distributions, followed by elastic plots of the throughthickness normal (s) and shear $\left(\mathrm{t}_{x y}\right)$ stresses of the bonded and weld-bonded joints ${ }^{y}$ at the adhesive mid-thickness and at the symmetry plane A-A (Fig. 2), for the $L_{O}$ values considered in the analysis. The stress distributions are normalized by $t_{\text {avg, the }}$ average shear stress along the overlap for the respective joint configuration [51].

\subsubsection{Welded joints}

Fig. 6 shows von Mises equivalent stresses at the spot-welded toints in the oyerlan region emphasizing the targe ioint tho tation

nugget periphery, as this is the primary region of plastic straining due to the sharp geometry change [23]; $\mathbf{s}_{y}$ stresses (Fig. 7a) are relevant only at the weld-nugget, and are caused by the asymmetric transmission of loads. The existence of peel $\mathbf{S}_{y}$ values at weld-nugget periphery and compressive ones in the inner regions is due to the joint curvature induced by the adherends rotation [31]. However, the weld-nugget transmits the loads between adherends mainly by shear (Fig. $7 \mathrm{~b}$ ), with peak $\mathrm{t}_{x y}$ stresses equally emerging at the nugget periphery by the effect of the sharp change of geometry $[31,52]$; $t_{x y}$ stresses are similar at the nearby regions of the nugget within the adherends, being nil away from this zone. 
a

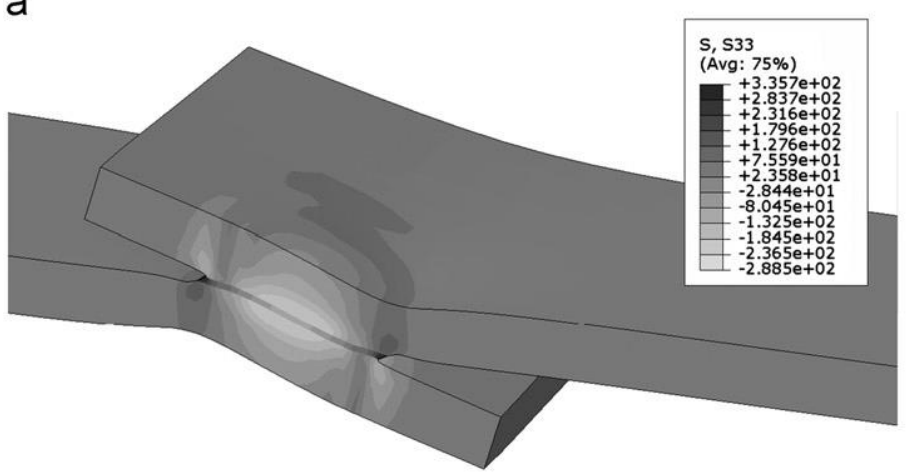

b

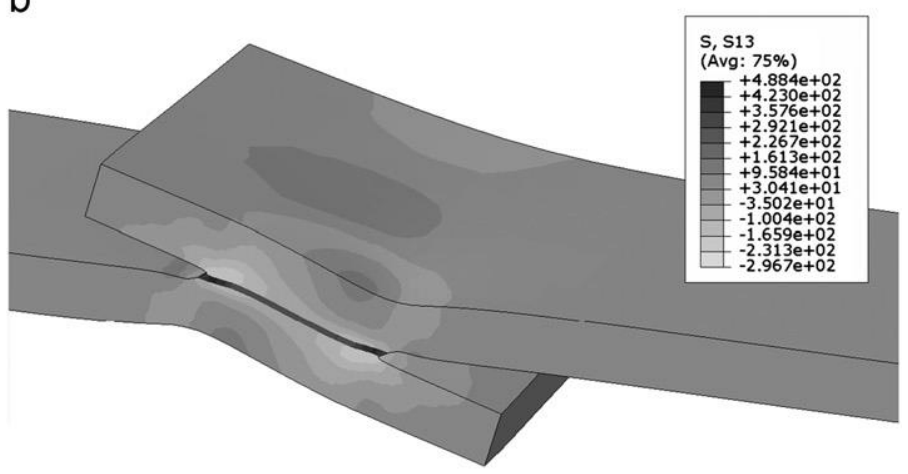

Fig. 7. $\mathrm{s}_{y}(\mathrm{a})$ and $\mathrm{t}_{x y}$ (b) stresses in the spot-welded joints in the overlap region (view of the symmetry plane).

a

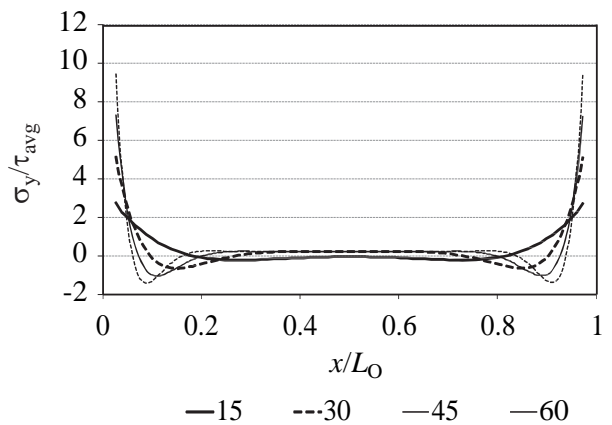

b

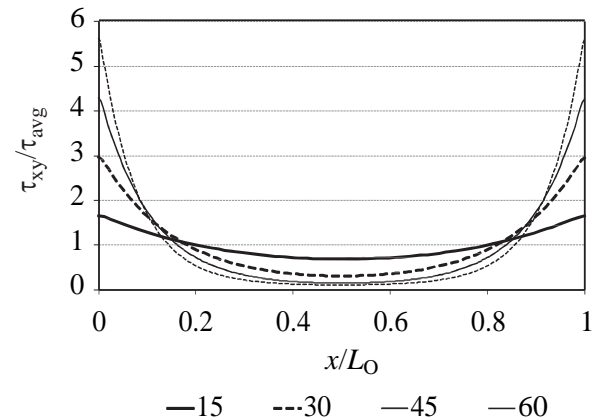

Fig. 8. Normalized plots of $\mathrm{S}_{y}$ (a) and $\mathrm{t}_{x y}$ (b) stresses for the bonded joints at the adhesive mid-thickness as a function of $x / L_{O}$.

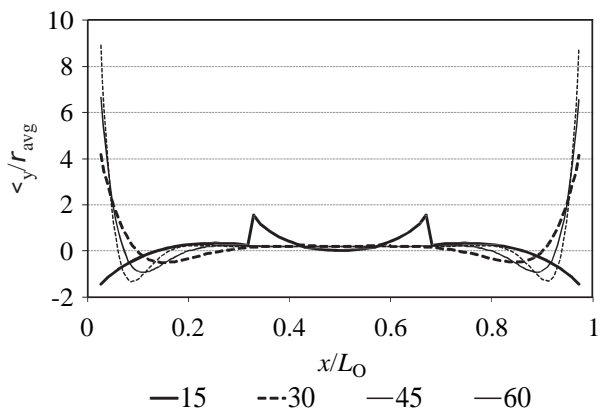

b

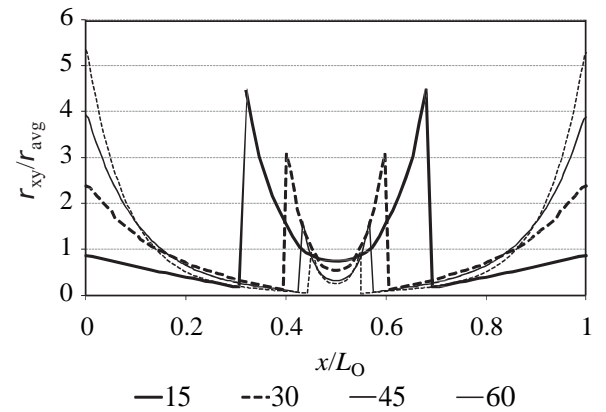

Fig. 9. Normalized plots of $\mathbf{S}_{y}(\mathrm{a})$ and $\mathrm{t}_{x y}$ (b) stresses for the weld-bonded joints at the adhesive mid-thickness as a function of $x / L_{0}$.

\subsubsection{Bonded joints}

$\mathrm{S}_{y}$ stress distributions (Fig. 8a) show singularities caused by the sharp overlap edges $[53,54]$. The observed profiles of $\mathbf{s}_{y}$ stresses emerge from the load eccentricity and joint rotation [55], resulting in the adherends separation at the overlap edges and compression in-between. Bigger $L_{O}$ values cause a concentration of peak $\mathbf{S}_{y}$ stresses in smaller normalized regions, also giving rise to $\mathbf{S}_{y}$ compressive stresses near the overlap edges; $\mathbf{S}_{y}$ stresses at the inner region of the overlap are nearly nil; $\mathrm{t}_{x y}$ stress distributions (Fig. 8b) report the classic concave shape peaking at the overlap edges, due to the diverging longitudinal deformation between the adherends along the overlap [56,57]; $\mathrm{t}_{x y}$ stress variations are negligible for $L_{O}^{1} 1 / 415 \mathrm{~mm}$, gradually increasing with $L_{O}$ because of higher longitudinal deformation gradients at the overlap [58]. This variation usually gives a non-linear increase of the failure load with $L_{O}$, especially for brittle adhesives that do not allow plasticization at the spots of stress concentrations $[35,36]$.
Ductile adhesives such as Araldite $^{\mathbf{s}} 2015$ are not as prone to these effects as brittle ones because of the allowable redistribution of stresses in the highly loaded regions when the yield strength is achieved [59].

\subsubsection{Weld-bonded joints}

The sole visible inconsistency on $\mathbf{S}_{y}$ stresses between the weld-bonded (Fig. 9a) and bonded joints (Fig. 8a) is found for $L_{O} 1 / 415 \mathrm{~mm}$, as the weld-nugget in weld-bonded joints supports all the peel $\mathbf{s}_{y}$ stresses, while $\mathbf{s}_{y}$ stresses in the surrounding bonded regions of the overlap are compressive, which benefits the adhesive layer, typically vulnerable to premature failures due to peel $[1,36]$. For bigger $L_{O}$ values, the majority of $\mathbf{s}_{y}$ stresses are transmitted by the adhesive layer [16]. Thus, on account of $\mathbf{s}_{y}$ stresses, the weld-bonded configuration is expected to give an advantage only for small $L_{O}$ values. On the other hand, $\mathrm{t}_{x y}$ stresses 
a

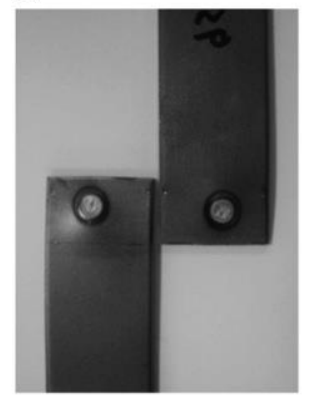

b

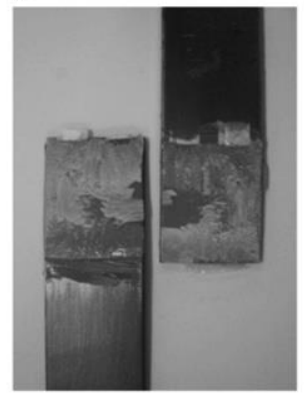

C

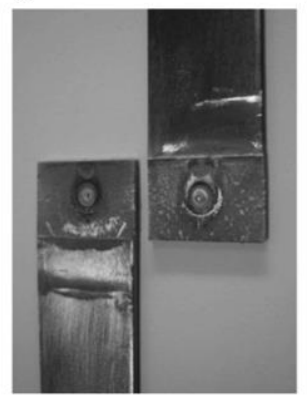

d

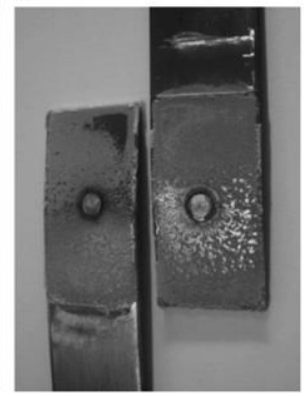

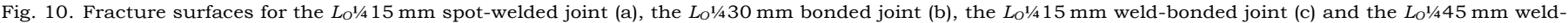
bonded joint (d).

a

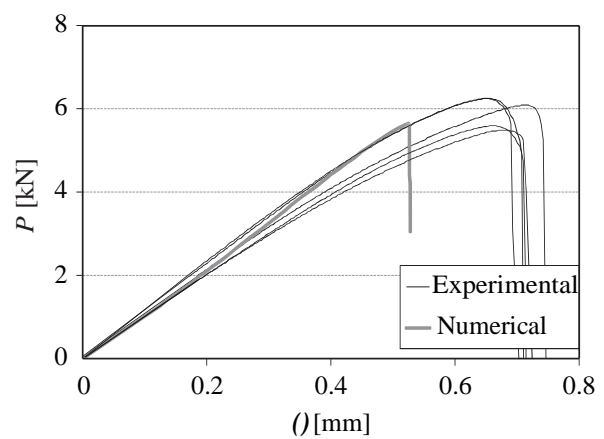

b

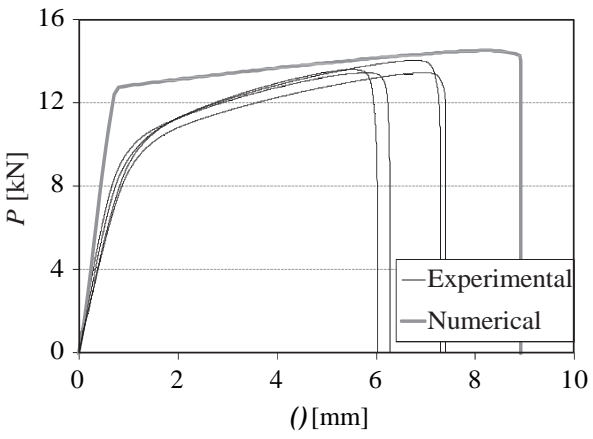

Fig. 11. Experimental and numerical $P$-d curves for the bonded joints with $L_{O}{ }^{1 / 4} 15 \mathrm{~mm}$ (a) and $L_{O} 1 / 460 \mathrm{~mm}$ (b).

(Fig. 9b) are largely affected by the weld-nugget and significantly differ from the bonded joint equivalents (Fig. 8b). Actually, due to the stiffness variation between the weld-nugget and the adhesive layer, by about two orders of magnitude, the weld-nugget acquires a very active role in the transmission of loads in a typically lightly loaded inner region of the overlap, inclusively holding much higher shear loads than the adhesive [23]. For $L_{O} 1 / 415 \mathrm{~mm}$, the nugget has the highest effect as it comprises $\mathbf{E}_{1 / 3}$ of $L_{O}$. For higher values of $L_{O}$, the nugget influence gradually diminishes, not only in terms of relative magnitude of stresses to the bonded region, but also in percentile area of influence along the overlap. Notwithstanding $L_{O}, \mathrm{t}_{x y}$ stresses along the nugget region peak at the periphery, identically to the welded joints (Fig. 7 b). Additionally, at the overlap edges, where loads are transmitted by the adhesive, $t_{x y}$ stresses equally peak due to differential deformation [31]. As in $\mathbf{s}_{y}$ stresses, $t_{x y}$ stresses also anticipate a strength improvement since, at the time of adhesive plasticization, the weldnugget transmits higher loads than the adhesive due to its higher stiffness. Compared to spot-welded joints, a reduction of $s_{y}$ and $t_{x y}$ stresses exists at the weld-nugget periphery due to the nearby adhesive [31].

\subsection{Fracture modes and strength of the joints}

Fig. 10 depicts representative fracture surfaces for the $L_{O} 1 / 415 \mathrm{~mm}$ spot-welded joint (a), the $L_{O} 1 / 430 \mathrm{~mm}$ bonded joint (b), the $L_{O^{1 / 4}} 15 \mathrm{~mm}$ weld-bonded joint (c) and the $L_{O} 1 / 445 \mathrm{~mm}$ weld-bonded joint (d). All bonded and weld-bonded joints fractures were cohesive in the bonded regions. Nonetheless, Fig. 10(c) and (d) clearly shows a burnt adhesive ring around the weld-nugget, corresponding to carbonization caused by the elevated temperatures during welding, and invariably leading to a reduction of the load-bearing capability of the joints $[22,28]$. However, this occurrence was always contained within 1-2 $\mathrm{mm}$ of the weld-nugget outer perimeter. The maximum load at first failure $\left(P_{m}\right)$ is introduced in the discussion for the evaluation of the joints strength, corresponding to the first drop of $P$, either nugget failure or debonding. Fig. 11 compares the experimental and FEM $P$-d curves for the bonded joints with $L_{O} 1 / 415 \mathrm{~mm}$ (a) and $L_{O} 1 / 460 \mathrm{~mm}$ (b), showing a close agreement. The $L_{O} 1 / 415 \mathrm{~mm}$ curves behave linearly up to failure (Fig. 11a), similar to the $L_{O} 1 / 430 \mathrm{~mm}$ bonded joints. Due to the large steel ductility (Fig. 1), for the $L_{O} 1 / 445$ and $60 \mathrm{~mm}$ (Fig. $11 \mathrm{~b}$ ) bonded joints the adherends endure large plasticization (beginning at $\mathrm{E} 10 \mathrm{kN}$ in the $P-\mathrm{d}$ plots) before cohesive failure of the adhesive. Fig. 12 relates to the experimental and FEM $P$-d curves of the weld-bonded joints, for $L_{O} 1 / 430 \mathrm{~mm}$ (a) and $L_{O} 1 / 445 \mathrm{~mm}$ (b). For the $L_{O} 1 / 415$ and $30 \mathrm{~mm}$ (Fig. 12a) weld-bonded joints, no adherend plasticization was found at $P_{m}$ (accompanied by a sudden drop of $P$ ), which was related to premature debonding. The weld-nugget continued to withstand loads before separation of the adherends at a similar load to the welded joints $[22,28]$. Equally to the collected data in this study, the results of Santos et al. [28] showed a slightly higher stiffness after $P_{m}$ for weld-bonded joints, compared to bonded joints, due to residual areas of adhesive bonding. Opposed to this behavior, the $L_{O} 1 / 445$ (Fig. $12 \mathrm{~b}$ ) and $60 \mathrm{~mm}$ weld-bonded joints failed after adherend plasticization (shortly after plasticization onset for $L_{O} 1 / 445 \mathrm{~mm}$ and largely after for $L_{O} 1 / 460 \mathrm{~mm}$ ). In general, although this is not directly comparable in the $P-\mathrm{d}$ plots of Figs. 11 and 12, the weld-bonded joints in this study exhibited a bigger global stiffness than bonded or spot-welded joints because of stiffening effects in the overlap region [28]. Fig. 13 shows $P_{m}$ as a function of $L_{O}$ for the bonded and weld-bonded joints, including the deviation for each tested configuration, against reasonably accurate FEM predictions. The range of experimental $P_{m}$ values of the spot-welded joints $\left(L_{O} 1 / 415 \mathrm{~mm}\right)$ is represented by the thickness of the black horizontal line of Fig. 13, whilst the corresponding numerical prediction gives 
a

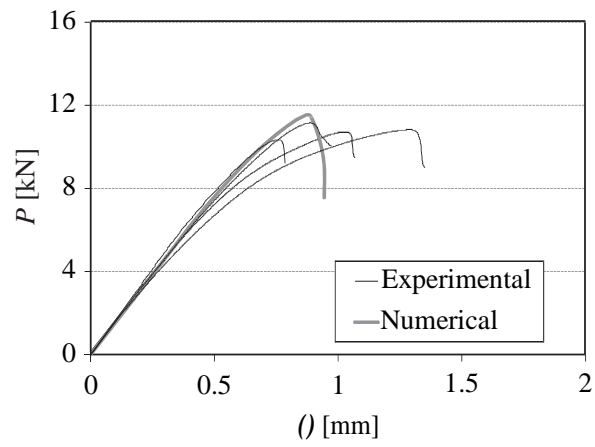

b

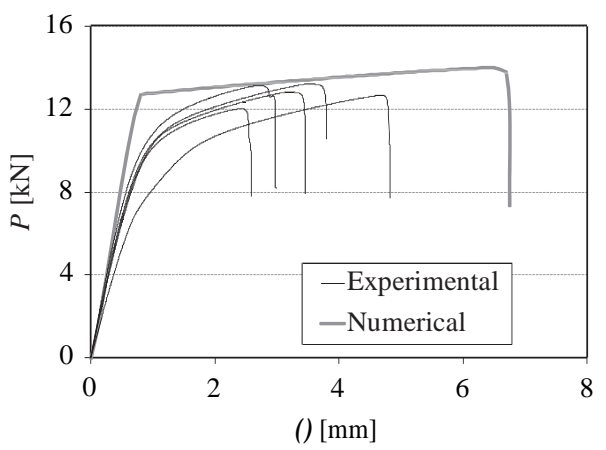

Fig. 12. Experimental and numerical $P$-d curves for the hybrid joints with $L_{O} 1 \frac{1}{4} 30 \mathrm{~mm}$ (a) and $L_{O}{ }^{1 / 4} 45 \mathrm{~mm}$ (b).

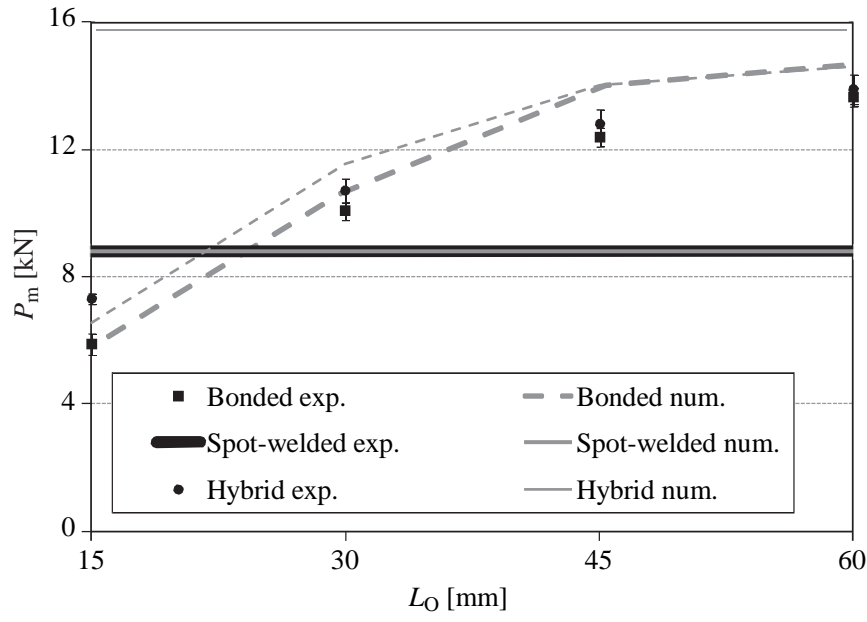

Fig. 13. Experimental/FEM comparison between the $P_{m}$ values as a function of $L_{O}$.

exactly the average of the experiments, because it was obtained by the previously mentioned fitting procedure. The bonded joints experienced an increase of $P_{m}$ at a decreasing rate with $L_{O}$, which is due to the adherends yielding from $L_{O} 1 / 445 \mathrm{~mm}$ to $L_{O} 1 / 460 \mathrm{~mm}$ (Fig. 11b). Otherwise, a nearly linear $P_{m}-L_{O}$ relationship would be expected, because of the high strength of the adherends and large ductility of the adhesive that help global yielding conditions at failure, due to the allowance of generalized yielding and redistribution of adhesive stresses [58,60-62]. Regarding the effectiveness of the traditional joining methods, the bonded joint surpasses the spot-welded joint for $L_{O} 1 / 430 \mathrm{~mm}$, which is closely related to the increase of bonded area with $L_{O}$. The weld-bonded joints show a non-negligible strength improvement over the bonded conditions for $L_{O} 1 / 415$ and $30 \mathrm{~mm}$, which is consistent with the stress analysis of Section 4.3 .3 (Fig. 9 vs. Fig. 8), since the weld-nugget provides a higher transfer of loads between the adherends at the time of cohesive failure of the adhesive. However, for bigger values of $L_{O}$, the values of $P_{m}$ are on the same order of magnitude of the bonded joints because of the elimination of the peel advantage (Fig. 9a vs. Fig. 8a), and also the reduction of the relative influence of the weld-nugget on $t_{x y}$ stresses averaged over the entire overlap (Fig. 9b). The adherend plasticization for the bigger $L_{O}$ values also helped this tendency, since any increase of the load bearing characteristics of the adhesive bond is also rendered less significant on $P_{m}$. Summarizing the strength advantage of weld-bonding compared to welded or bonded joints, for $L_{O} 1 / 415 \mathrm{~mm}$ a $24 \%$ improvement was found to the bonded joint (obtained from the experimental data; valid throughout this section), although no improvement occurred in relation to the welded joint because of premature failure of the adhesive induced by the adherends separation [63]. For $L_{O^{1 / 4}} 30 \mathrm{~mm}$, the weld-bonded joint provides a $6.4 \%$ improvement to the bonded joint and a $22 \%$ increase of $P_{m}$ to the welded joint, the latter occurring by failure of the adhesive at a higher $P_{m}$ value than the spot-welded joint equivalent. Opposed to this behavior, for bigger values of $L_{O}$, the strength advantage of the weld-bonded joint to the bonded one is smaller $\left(3.3 \%\right.$ for $L_{O} 1 / 445 \mathrm{~mm}$ and $1.8 \%$ for $L_{O} 1 / 460 \mathrm{~mm}$ ), while the improvement of the technique to the spot-welded joints is $46 \%\left(L_{O} 1 / 445 \mathrm{~mm}\right)$ and $58 \%\left(L_{O} 1 / 460 \mathrm{~mm}\right)$. The global results presented in this section showed the suitability of the FEM and CZM for the simulation of bonded, welded and weldbonded joints (maximum deviation of $12 \%$ for the $L_{O} 1 / 445 \mathrm{~mm}$ bonded joint), thus aiding quicker, more effective and cheaper design of bonded joints, but the quantitative results and relative advantages between all techniques should be considered valid only for the particular set of geometric and material conditions selected for this study. Actually, for stronger adherends, a substantial increase of $P_{m}$ is expected for the bigger values of $L_{O}$ as they would prevent adherend plasticization. As regards the adhesive layer, Darwish and Al-Samhan [16] showed the major influence of $E$ (of the adhesive) on $P_{m}$, as adhesives with smaller values of $E$ maximize the joints strength because they allow the weld-nugget to support the majority of the loads whilst the adhesive bond undergoes larger strains and, thus, allowing bigger joint loads before failing. The mentioned authors concluded as well that the increase of $t_{A}$ is also effective to reduce stress concentrations at the weld-nugget periphery and at the overlap edges, which reflects on higher values of $P_{m}$, while bigger values of $E$ for the adherends effectively reduce peel and shear peak stresses, increasing the strength of hybrid joints.

\section{Conclusions}

An experimental and an FEM study were carried out on hybrid spot-welded/bonded single-lap joints, by comparison with the spot-welded and adhesively bonded equivalents, for the evaluation of this technique and the capability of CZM for design purposes. The study began with an influence analysis of the welding parameters on the strength of spot-welded joints and on the visible adhesive degradation by welding-induced heating, which allowed selecting the most suitable conditions. After proper characterization of the CZM laws of the adhesive and weld-nugget, a FEM stress analysis provided a background for further discussion and showed, for the welded joints, $\mathbf{s}_{y}$ and $t_{x y}$ stress concentrations at the weld-nugget periphery and also a large rotation of the adherends and consequent separation at the overlap edges; $s_{y}$ and $t_{x y}$ stresses for the bonded joints peaked at the overlap edges, while weld-bonded joints benefit from higher 
transmission of $t_{x y}$ loads in the inner overlap region by the weldnugget, because of the stiffness differential to the bonded region. The strength comparisons between the three joint techniques showed a marked advantage of weld-bonding over the traditional equivalents for $L_{O}{ }^{1 / 430} \mathrm{~mm}$. For $L_{O} 1 / 415 \mathrm{~mm}$, the improvement was found only in comparison with the bonded joint, because of premature failure of the adhesive bond. Bigger values of $L_{O}$ revealed a smaller influence on the strength improvement to the bonded joints due to the adherends plasticization for the achieved $P_{m}$ values and stress distribution issues, even though they were recommended over spot-welding. Although the presented results cannot be directly extrapolated to other geometries and materials without a specific analysis, validation of the proposed FEM/CZM technique for the design of bonded, welded and hybrid joints was successfully accomplished.

\section{References}

[1] Campilho RDSG, de Moura MFSF, Domingues JJMS. Modeling single and double lap repairs on composite materials. Compos Sci Technol 2005;65:194858

[2] Campilho RDSG, de Moura MFSF, JJMS Domingues, Morais JJL. Computational modelling of the residual strength of repaired composite laminates using a cohesive damage model. J Adhes Sci Technol 2008;22:1565-91.

[3] Baldan A. Adhesively-bonded joints and repairs in metallic alloys, polymers and composite materials: adhesives, adhesion theories and surface pretreatment. J Mater Sci 2004;39:1-49.

[4] Doyle G, Pethrick RA. Environmental effects on the ageing of epoxy adhesive joints. Int J Adhes Adhes 2009;29:77-90.

[5] Banea MD, da Silva LFM, Campilho RDSG. Temperature dependence of the fracture toughness of adhesively bonded joints. J Adhes Sci Technol 2010;24:2011-26.

[6] da Silva LFM, Pirondi A, Ochsner A. Hybrid adhesive joints. Heidelberg: Springer; 2011.

[7] Darwish SMH, Ghanya A. Critical assessment of weld-bonded technologies. J Mater Process Technol 2000;105:221-9.

[8] Moroni F, Pirondi A, Kleiner F. Experimental analysis and comparison of the strength of simple and hybrid structural joints. Int $\mathrm{J}$ Adhes Adhes 2010;30:367-79.

[9] Gomez S, Onoro J, Pecharroman J. A simple mechanical model of a structural hybrid adhesive/riveted single lap joint. Int J Adhes Adhes 2007;27:263-7.

[10] Kelly G. Quasi-static strength and fatigue life of hybrid (bonded/bolted) composite single-lap joints. Compos Struct 2006;72:119-29.

[11] Lee YH, Lim DW, Choi JH, Kweon JH, Yoon MK. Failure load evaluation and prediction of hybrid composite double lap joints. Compos Struct 2010;92:2916-26.

[12] Hart-Smith LJ. Design methodology for bonded-bolted composite joint. Technical report AFWAL-TR-81-3154. Douglas Aircraft Company; 1982.

[13] Kelly G. Load transfer in hybrid (bonded/bolted) composite single-lap joints. Compos Struct 2005;69:35-43.

[14] Mann JY, Pell RA, Jones R, Heller M. Reducing the effects of rivet holes on fatigue life by adhesive bonding. Theor Appl Fract Mech 1985;3:113-24.

[15] Al-Samhan A, Darwish SM. Finite element modelling of weld-bonded joints. J Mater Process Technol 2003;142:587-98.

[16] Darwish SM, Al-Samhan A. Design rationale of weld-bonded joints. Int $\mathrm{J}$ Adhes Adhes 2004;24:367-77.

[17] Chang B, Shi Y, Lu L. Studies on the stress distribution and fatigue behaviour of weldbonded lap shear joints. J Mater Process Technol 2001;108:307-13.

[18] Melander A, Larsson M, Stensio H, Gustavsson A, Linder J. Fatigue performance of weldbonded high strength sheet steels tested in Arctic, room temperature and tropical environments. Int J Adhes Adhes 2000;20:415-25.

[19] Nied HA. The finite element modelling of the resistance spot welding process. Weld J 1984;63:123-32.

[20] Chang HS, Cho HS. A study on the shunt effect in resistance spot welding. Weld J 1990;69:308-17.

[21] Pocius AV. Adhesion and adhesives technology. New York: Hanser; 1997.

[22] Chang B, Shi Y, Dong S. Studies on a computational model and the stress field characteristics of weldbonded joints for a car body steel sheet. J Mater Process Technol 2000;100:171-8.

[23] Darwish SM, Al-Samhann A. Peel and shear strength of spot-welded and weldbonded dissimilar thickness joints. J Mater Process Technol 2004 519.

[24] Schwartz MM. Metals joining manual book. New York: McGraw Hill; 1979.

[25] Darwish SM. Weld bonding strengthens and balances the stresses in spotwelded dissimilar thickness joints. J Mater Process Technol 2003;134: 35262

[26] Dai RL, Wang W, Li CZ. Research on weld-bonding technique and its best technology. J Mech Strength 1996;18:64-7.
[27] Heidi B, El-Sebakhy I, Malik D Weldbonding of structural adhesives for body stiffening. In: Proceedings of the Worldwide passenger car Conference, USA 1992.

[28] Santos IO, Zhang W, Gonc-alves VM, Bay N, Martins PAF. Weld bonding of stainless steel. Int J Mach Tool Manuf 2004;44:1431-9.

[29] Charbonnet P, Clad A, Fant-Jaeckels H, Thirion JL Weld bonding: a very well adapted joining technique to decrease the weight of steel structures. In: Proceedings of La Revue de Mé tallurgie - CIT 2000; April. p. 543-51.

[30] Darwish SM. Characteristics of weld-bonded commercial aluminium sheets (B.S. 1050). Int J Adhes Adhes 2003;23:169-76.

[31] Al-Samhann A, Darwish SM. Strength prediction of weld-bonded joints. Int J Adhes Adhes 2003;23:23-8.

[32] Darwish SM. Analysis of weldbonded dissimilar materials. Int J Adhes Adhes 2004;24:347-54

[33] Campilho RDSG, de Moura MFSF, Ramantani DA, Morais JJL, Domingues JJMS. Buckling strength of adhesively-bonded single and double-strap repairs on carbon-epoxy structures. Compos Sci Technol 2010;70:371-9.

[34] Campilho RDSG, de Moura MFSF, Ramantani DA, Morais JJL, AMJP Barreto, Domingues JJMS. Adhesively-bonded repair proposal for wood members damaged by horizontal shear using carbon-epoxy patches. J Adhes 2010;86: 649-70.

[35] Campilho RDSG, Pinto AMG, Banea MD, Silva RF, da Silva LFM. Strength improvement of adhesively-bonded joints using a reverse-bent geometry. J Adhes Sci Technol 2011;25:2351-68.

[36] Campilho RDSG, Banea MD, Pinto AMG, da Silva LFM, de Jesus AMP. Strength prediction of single- and double-lap joints by standard and extended finite element modeling. Int J Adhes Adhes 2011;31:363-72.

[37] da Silva LFM, da Silva RAM, Chousal JAG, Pinto AMG. Alternative methods to measure the adhesive shear displacement in the thick adherend shear test. J Adhes Sci Technol 2008;22:15-29.

[38] Campilho RDSG, de Moura MFSF, Ramantani DA, Morais JJL, DominguesJJMS. Tensile behaviour of three-dimensional carbon-epoxy adhesively-bonded single and double-strap repairs. Int J Adhes Adhes 2009;29:678-86.

[39] Hills DR, Parker JD, Williams NT. Effect of welds in spot welded and weldbonded arrays on static failure load of individual spot welds and adhesive bond. Ironmaking Steelmaking 1996;23:150-6.

40] Campilho RDSG, de Moura MFSF, Pinto AMG, Morais JJL, Domingues JJMS. Modelling the tensile fracture behaviour of CFRP scarf repairs. Compos B - Eng 2009;40:149-57.

41] Radaj D. Stress singularity, notch stress and structural stress at spot-welded joints. Eng Fract Mech 1989;34:495-506.

[42] Radaj D, Soegiharto S. Structural concentration at spot-welded joints: improved model, comparison of results, stress singularity. Welding World 1990;28:183-9.

[43] Banea MD, da Silva LFM. The effect of temperature on the mechanical properties of adhesives for the automotive industry. Proc Inst Mech Eng L:J Mat Des Appl 2010;224:51-62.

[44] Campilho RDSG, Banea MD, Chaves FJP, da Silva LFM. Extended Finite Element Method for fracture characterization of adhesive joints in pure mode I. Comput Mater Sci 2011;50:1543-9.

[45] Goyal VK, Johnson ER, Goyal VK. Predictive strength-fracture model for composite bonded joints. Compos Struct 2008;82:434-46.

[46] Campilho RDSG, de Moura MFSF, Ramantani DA, Morais JJL, DominguesJJMS Buckling behaviour of carbon-epoxy adhesively-bonded scarf repairs. J Adhes Sci Technol 2009;23:1493-513.

[47] Campilho RDSG, de Moura MFSF, AMJP Barreto, Morais JJL, Domingues JJMS. Fracture behaviour of damaged wood beams repaired with an adhesivelybonded composite patch. Compos A - Appl Sci Manuf 2009;40:852-9.

[48] Abaqus ${ }^{\text {s }}$ HTML Documentation. Dassault Systemes, 2009.

[49] Campilho RDSG, de Moura MFSF, Domingues JJMS. Using a cohesive damage model to predict the tensile behaviour of CFRP single-strap repairs. Int J Solids Struct 2008;45:1497-512.

[50] Jing J, Gao F, Johnson J, Liang FZ, Williams RL, Qu J. Simulation of dynamic fracture along solder-pad interfaces using a cohesive zone model. Eng Failure Anal 2009;16:1579-86.

[51] Campilho RDSG, de Moura MFSF, AMJP Barreto, Morais JJL, Domingues JJMS Experimental and numerical evaluation of composite repairs on wood beams damaged by cross-graining. Constr Build Mater 2010;24:531-7.

[52] Chang B, Shi Y, Dong S. Comparative studies on stresses in weld-bonded, spot-welded and adhesive-bonded joints. J Mater Process Technol 1999;87:230-6.

[53] Shin KC, Lee JJ. Bond parameters to improve tensile load bearing capacities of co-cured single and double lap joints with steel and carbon-fiber-epoxy composite adherends. J Compos Mater 2003;37:401-20.

54] Radice J, Vinson J. On the use of quasi-dynamic modeling for composite materia structures: analysis of adhesively bonded joints with midplane asymmetry and transverse shear deformation. Compos Sci Technol 2006;66:2528-47.

[55] Pinto AMG, Magalha es AG, RDSG Campilho, de Moura MFSF, Baptista APM. Single-lap joints of similar and dissimilar adherends bonded with an acrylic adhesive. J Adhes 2009;85:351-76.

[56] Volkersen O. Die nietkraftoerteilung in zubeanspruchten nietverbindungen konstanten loschonquerschnitten. Luftfahrtforschung 1938;15:41-7.

[57] Adams RD, Comyn JC, Wake WC. Structural adhesive joints in engineering. 2nd ed. London, UK: Chapman \& Hall; 1997.

[58] Hu FZ, Soutis C. Strength prediction of patch repaired CFRP laminates loaded in compression. Compos Sci Technol 2000;60:1103-14. 
[59] McGeorge D. Inelastic fracture of adhesively bonded overlap joints. Eng Fract Mech 2010;77:1-21.

[60] John SJ, Kinloch AJ, Matthews FL. Measuring and predicting the durability of bonded carbon fibre/epoxy composite joints. Composites 1991;22:121-6.

[61] da Silva LFM, Critchlow GW, Figueiredo MAV. Parametric study of adhesively bonded single lap joints by the Taguchi Method. J Adhes Sci Technol 2008;22:1477-94.
[62] da Silva LFM, Carbas RJC, Critchlow GW, Figueiredo MAV, Brown K. Effect of material, geometry, surface treatment and environment on the shear strength of single lap joints. Int J Adhes Adhes 2009;29:621-32.

[63] Gonc-alves VM, Martins PAF. Static and fatigue performance of weld-bonded stainless steel joints. Mater Manuf Process 2006;21:774-8. 